\title{
Interactions between real and subjective contours in the Bourdon illusion
}

\author{
JAMES T. WALKER and MATTHEW D. SHANK \\ University of Missouri-St. Louis, St. Louis, Missouri
}

\begin{abstract}
The Bourdon illusion is a contour-attraction effect in which two colinear test edges of a plane figure appear displaced toward a bent induction edge located nearby. This illusion and related effects are stronger in subjective contours than in real contours. In Bourdon figures combining both varieties of contours, real induction contours produced a strong illusion in subjective test contours, but subjective induction contours produced no illusion in real test contours. Thus, interactions between real and subjective contours were asymmetrical. Luminance contrast between real and subjective contours weakened the Bourdon illusion.
\end{abstract}

Subjective contours are illusory lines or edges occurring in physically homogeneous regions lacking any objective gradients of hue or luminance (Kanizsa, 1955, 1979; Ware, 1981). Figure 1A shows two slender subjective triangles placed apex to apex with two of their long sides in line with each other. The broken circles and black disks are the inducing elements that produce the edges of the subjective triangles. The aligned, or colinear, edges of the two triangles appear displaced toward the nonaligned edges, thus representing a subjective-contour form of the Bourdon illusion (Walker \& Shank, 1987). We will refer to the colinear edges in such a figure as the test contours, and to the nonaligned, or bent, edges as the induction contours.

In its more conventional forms, the Bourdon illusion is presented as a solid black or white figure against a contrasting background, or as an outline, as shown in Figure 1G (Bourdon, 1902; Jastrow, 1891). Outline figures produce weaker Bourdon illusions, and sometimes produce apparent displacements in the opposite direction-that is, the test contours sometimes appear displaced away from the induction contours in outline figures (Luckiesh, 1922/1965, p. 92; Rozvany \& Day, 1980; Wenderoth \& O'Connor, $1987 \mathrm{~b}$; Wenderoth, O'Connor, $\&$ Johnson, 1986). Solid figures produce stronger Bourdon illusions, and subjective contours produce still greater effects (Walker \& Shank, 1987).

Several other illusions also occur in subjective contours-for example, the Ponzo (Farné, 1968), the Zöllner (Pastore, 1971), the Poggendorff (Goldstein \& Weintraub, 1972; Meyer \& Garges, 1979), and perspective reversal in the Necker cube (Bradley \& Petry, 1977). However, these illusions are weaker in subjective contours, whereas the Bourdon illusion is stronger.

Visual contours repel each other in many situations, such as in the Zöllner illusion and in the tilt illusion. However, the Bourdon illusion is predominantly a

The authors' mailing address is Department of Psychology, University of Missouri, St. Louis, MO 63121.

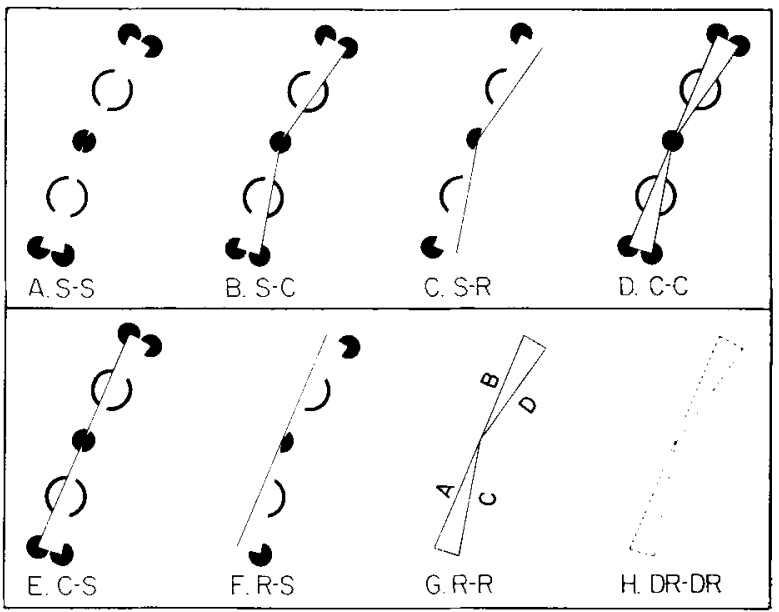

Figure 1. Ilusion figures in Experiments 1 and 2. The first letters identify the colinear test contours and the second letters identify the bent induction contours. (A) S-S, subjective, subjective; (B) S-C, subjective, composite; (C) S-R, subjective, real; (D) C-C, composite, composite; (E) C-S, composite, subjective; (F) R-S, real, subjective; (G) R-R, real, real; and (H) DR-DR, dashed real, doshed real. Figures 1A-1G were used in Experiment 1, and Figure $1 \mathrm{H}$ in Experiment 2.

contour-attraction effect. Under most conditions, the colinear test contours, A and B in Figure 1G, appear displaced toward the bent induction contours ( $C$ and $D)$. In addition, the objectively bent induction contours appear displaced-partially unbent-in the direction of the colinear test edges (Walker \& Shank, 1987).

We will refer to the apparent displacement of the colinear test edges as the Bourdon illusion, and to the apparent displacement of the bent induction edges as the unbending effect. These apparent displacements involve mutual attraction or assimilation between induction and test contours, and thus each effect represents a special case of a contour-attraction process.

In our previous study of the Bourdon illusion, the test and induction contours within each illusion figure were 
of the same kind, either real or subjective. The present study assessed interactions between different kinds of test and induction contours, real and subjective, within illusion figures. Experiment 1 assessed the interactions between several combinations of subjective contours and real contours consisting of solid lines, as in Figures $\mathrm{IC}$ and 1F. In Experiment 2, the real contours consisted of dashed, or broken, lines, as in Figure 1H. Experiment 3 measured the effects of luminance contrast on contour interactions using black and white figures on gray backgrounds.

\section{EXPERIMENT 1}

This experiment measured the Bourdon illusion and the unbending effect using the stimuli described below. Subjects indicated the extent of apparent displacement in these illusion figures by choosing among a set of objectively bent comparison stimuli.

\section{Method}

Subjects. Nine male and 9 female undergraduate psychology students at the University of Missouri-St. Louis, received extra course credit for participating in this experiment. Their ages ranged from 18 to 23 , and the mean age was 19.4 years.

Stimuli. Figure 1 shows the illusion stimuli used in the present experiment. Each figure consisted of a particular combination of the following kinds of induction and test contours: real contours, solid black lines, as in Figure 1G; subjective contours, the edges of Kanizsa-type subjective figures, as in Figure 1A; and composite contours, which are subjective contours filled in with real lines, as in Figure 1D.

In identifying the illusion stimuli in Figure 1, the first letter refers to the colinear test contours and the second to the objectively bent induction contours: $\mathrm{S}-\mathrm{S}$ (subjective, subjective); S-C (subjective, composite); S-R (subjective, real); C-C (composite, composite); C-S (composite, subjective); R-S (real, subjective); and R-R (real, real). Figure 1H, designated DR-DR (dashed real, dashed real), was used in Experiment 2 and will be described later.

Each figure consisted of two isosceles triangles with longer sides of $12.7 \mathrm{~cm}$ and apex angles of $12.5^{\circ}$. The figures were oriented as shown with the colinear edges making an angle of $22.5^{\circ}$ with the vertical. This combination of apex angle and orientation previously produced the greatest Bourdon illusion in real contours (Rozvany \& Day, 1980), and was also used for consistency with our previous study of the illusion in subjective contours (Walker \& Shank, 1987).

Figure 2 shows the series of 15 comparison stimuli used in judging the apparent displacements in the illusion figures. The middle member of the series, Comparison 8 , was a straight line of the same length and orientation as the colinear contours of the illusion figures-that is, $25.4 \mathrm{~cm}$ long, and oriented $22.5^{\circ}$ from the vertical. The other comparison stimuli were the same length, but were bent in the middle. Progressing upward and downward from Comparison 8 , the amount of bending in successive comparison stimuli increased in $5^{\circ}$ steps. Thus, for Comparisons 8 through 15, the degrees of bending were $0^{\circ}, 5^{\circ}, 10^{\circ}, 15^{\circ}, 20^{\circ}, 25^{\circ}, 30^{\circ}$, and $35^{\circ}$. We used similar comparison stimuli earlier (Walker \& Shank, 1987), but the present stimuli covered a wider range of bending.

Each illusion was presented separately at a viewing distance of $2 \mathrm{~m}$, approximately at eye level, on a modified music stand inclined $8.5^{\circ}$ from the vertical. The comparison stimuli were suspended from the lower edge of the stand, and were in a frontoparallel plane. The center of the comparison display was located $34 \mathrm{~cm}$ below the center of each illusion figure. The illusion figures and comparison stimuli all subtended a visual angle of about $7^{\circ}$ measured end to end. The displays were lighted by overhead fluorescent lights providing a luminance of about $210 \mathrm{~cd} / \mathrm{m}^{2}$ on the white background of the illusion figures and about $120 \mathrm{~cd} / \mathrm{m}^{2}$ on the comparison stimuli, as measured by a Macbeth illuminometer.

Procedure. To familiarize the participants with subjective contours, they were shown an equilateral subjective triangle (Kanizsa, 1979). All of the subjects reported seeing the subjective triangle. This figure was also shown with real lines added, as in the style of our Figure 1D. Each subject then viewed the seven illusion figures in an individually randomized sequence. The subjects indicated the extent of apparent bending of the colinear test contours and the objectively bent induction contours by choosing the appropriate comparison stimuli. The order in which the test and induction contours were judged was also randomized individually. The subjects were free to choose fractional values between adjacent comparison stimuli, but none did.

\section{Results and Discussion}

If the Bourdon illusion occurs in the expected direction, then the colinear test contours ( $A$ and $B$ in Figure 1G) will appear displaced inward in the direction of the bent induction contours (C and D). In that case, the subject will equate the apparent bending of the colinear contours with a comparison stimulus greater than 8 (see Figure 2).

If the unbending effect occurs, then the objectively bent induction contours $\mathrm{C}$ and $\mathrm{D}$ will appear displaced in the direction of the colinear test contours. In that case, the subject will equate the appearance of the bent contours with a comparison stimulus less than 13 , which represents the objective $25^{\circ}$ angle between these contours. Responses in the direction indicating contour attraction were considered positive for both the colinear test contours and the bent induction contours, and responses in the other direction were considered negative.

Since the means and standard deviations were correlated, and since there were some negative scores and scores of zero, the data were transformed by taking log $(X+10)$ before doing a $2 \times 7$ analysis of variance with

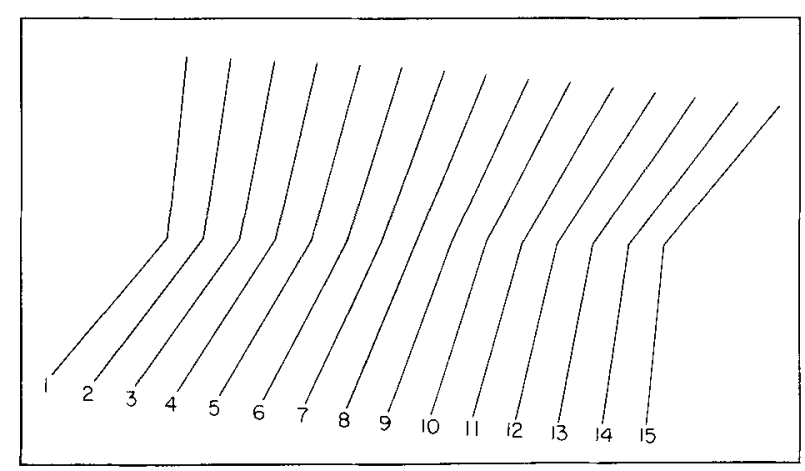

Figure 2. Comparison stimuli in Experiments 1 and 2. Lines are progressively bent in $5^{\circ}$ increments. 
repeated measures on both factors. The factors were kinds of edges (colinear test, bent induction) and illusion figures representing different combinations of induction and test contours (S-S, S-C, S-R, C-C, C-S, R-S, and R-R).

There was no significant main effect of kinds of edges $(F<1)$, and thus no significant overall difference between the Bourdon illusion and the unbending effect. There was a highly significant main effect of the kinds of illusion figures $[F(6,102)=18.04, p<.001]$, and an edge $\times$ figure interaction $[F(6,102)=49.37$, $p<.001]$.

Figure 3 shows the mean apparent displacement of the test and induction contours in all of the illusion figures. Figure R-R produced a small Bourdon illusion $[t(17)=$ $2.20, p<.05]$, and Figures $\mathrm{C}-\mathrm{C}$ and $\mathrm{S}-\mathrm{S}$ produced larger effects [both values of $t(17) \geq 12.91, p<.001$ ] The Bourdon illusion differed significantly among these figures by Newman-Keuls tests at the .01 and .05 levels. For Figure S-S, the colinear test contours appeared bent by $8.32^{\circ}$, and the objectively bent induction contours appeared unbent by exactly that amount $[t(17)=7.29$, $p<.001]$. Thus, the Bourdon illusion occurred in a figure consisting wholly of subjective contours, and furthermore, the bent induction contours were attracted by the straight test contours to the same extent that the induction contours attracted the test contours. These measures are comparable to our earlier results using the same illusion figure (Walker \& Shank, 1987).

A significant Bourdon illusion also occurred in Figures S-R and S-C, in which the subjective colinear test contours appeared displaced toward the real or composite bent induction contours [both values of $t(17) \geq 9.72$, $p<.001]$. However, there was no significant unbending effect in these figures. Thus, the subjective colinear test contours were attracted by the real and composite induction lines, but the subjective test contours produced

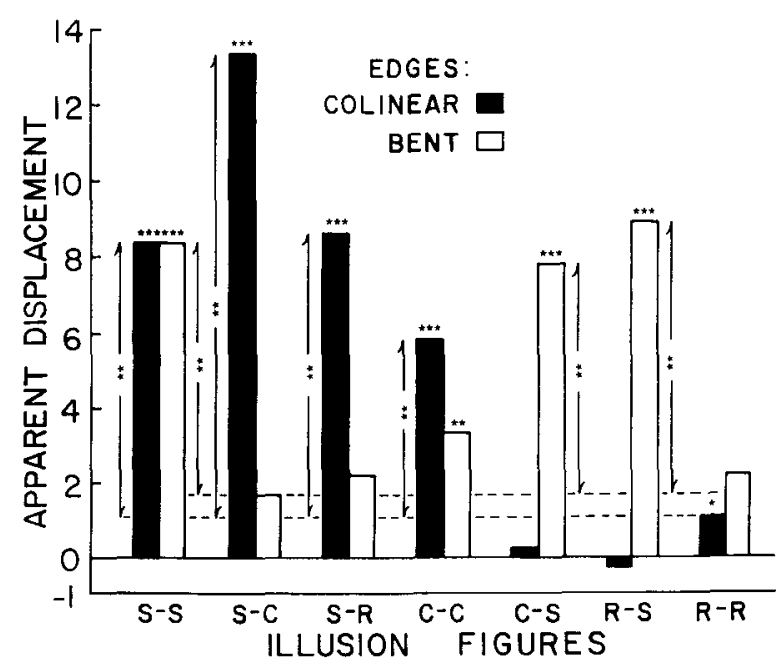

Figure 3. Results of Experiment 1. Abbreviations in illusion labels are defined in the caption of Figure 1 . Asterisks at tops of bars indicate values significantly different from zero $\left({ }^{*} p<.05,{ }^{* *} p<.01\right.$, $* * * p<.001)$. Asterisks inside arrows indicate the significance of selected Newman-Keuls comparisons. no significant apparent displacement of the real or composite induction contours.

In Figures $\mathrm{R}-\mathrm{S}$ and $\mathrm{C}-\mathrm{S}$, in which the test contours were respectively real and composite, the subjective induction contours produced no significant Bourdon illusion. But in both of these figures the subjective induction contours appeared displaced-partially unbent-in the direction of the colinear test contours [both values of $t(17) \geq 6.02$, $p<.001]$.

The interactions between real and subjective contours were asymmetrical in that real contours attracted subjective contours to a greater extent than subjective contours attracted real contours. Another kind of asymmetry between real and subjective contours has been previously reported. Practice in judging the orientation of subjective contours transferred positively to judgments of real contours, but the reverse was not true (Vogels \& Orban, 1987). To the extent that our results can be compared to this perceptual learning phenomenon, the direction of our interaction-real contours strongly influencing subjective contours, but not the reverse-appears opposite to the asymmetrical interaction that Vogels and Orban reported.

Figure R-R, an outline figure having real induction and test contours, produced only a small Bourdon illusion and no significant unbending of the induction lines. In Figure $\mathrm{C}-\mathrm{C}$, the composite induction and test contours combined the features of real and subjective contours and indeed produced intermediate levels of the Bourdon illusion and the unbending effect in relation to Figures $R-R$ and $\mathbf{S}-\mathrm{S}$.

Our finding of a small Bourdon illusion in Figure R-R is consistent with the earlier results of Rozvany and Day (1980), but contrary to the results of Wenderoth and O'Connor (1987b) and Wendoroth et al. (1986), who found significant repulsion effects in real outline figures. In solid figures, Wenderoth and O'Connor (1987b) found significant Bourdon illusions when the test contours were colinear, but there was no apparent displacement when the test contours were objectively bent. However, we found significant displacements-unbending-in our objectively bent induction contours in four of the seven illusions in the present experiment (see Figure 3). Thus, our results are not entirely consistent with those of Wenderoth et al.

There are many differences between the conditions in the present experiment and the above studies of Wenderoth et al. (1986), for example, in the size, luminance, and contrast of the stimuli, and particularly in the measurement procedures. Our measurement procedure used an array of comparison stimuli centered $9.7^{\circ}$ below each illusion, whereas Wenderoth et al. used an adjustable comparison line centered at a distance of $.3^{\circ}$ to $1.2^{\circ}$ to the upper left of the test contours.

As we noted in the introductory section, subjective contours have produced weaker effects in earlier studies of other illusions. In the Ponzo illusion (Farné, 1968), and in the Poggendorff illusion (Goldstein \& Weintraub, 1972; Meyer \& Garges, 1979), the test contours were real lines and the induction contours were subjective. In light of our 
present results, this combination of real test contours and subjective induction contours might be expected to produce weaker illusions.

We found a variety of illusion occurring within the comparison stimuli, as in our earlier study. In Figure 2, the midpoints of the comparison lines-the points where the lines bend-are aligned horizontally. However, the midpoints of the lines on the right side of the display look higher than the midpoints on the left. After judging the Bourdon illusion figures, 16 of the 18 subjects indicated that the midpoints looked higher on the right $(Z=3.06$, $p<.01)$. There is no indication that such an illusion of vertical displacement impairs the usefulness of the comparison stimuli in measuring the Bourdon illusion and the unbending effect.

In our earlier paper, we offered a possible explanation of this illusion in the comparison stimuli (Walker \& Shank, 1987). If the subjective vertical were displaced in the direction of the axes of the comparison stimulithat is, rotated $22.5^{\circ}$ clockwise-then the horizontally aligned midpoints of these stimuli would appear higher on the right side of the display. Thus, the illusion may be due to a tilted frame-of-reference effect (Gibson \& Radner, 1937). Some of the features of the Poggendorff illusion may also apply here (for example, see the Poggendorff variants in Coren \& Girgus, 1978, p. 60; and Pressey \& den Heyer, 1968).

\section{EXPERIMENT 2}

Rozvany and Day (1980) found little or no Bourdon illusion in figures consisting of dashed lines, or in combinations of dashed and solid lines. The present experiment was designed to assess the interactions between subjective contours and real contours consisting of dashed lines.

\section{Method}

Subjects. Eight male and 8 female undergraduate psychology students participated in this experiment for extra course credit. Their ages ranged from 18 to 37 , and the mean age was 21.42 years.

Stimuli. The same combinations of real, subjective, and composite contours were used as in Experiment 1, but the solid lines in the real and composite contours were replaced with dashed lines. Otherwise, the illusion stimuli were of the same configurations as Figures $1 \mathrm{~A}$ through $1 \mathrm{G}$. Figure $1 \mathrm{H}$ shows the dashed-line realcontour illusion figure in this experiment, designated DR-DR. The dashed lines in the other stimuli were like the dashed lines in this figure.

The present figures are identified as in Experiment 1, except here the letter D stands for dashed lines in the real and composite contours. The first letters refer to the colinear test contours and the second letters refer to the induction contours: $S-S$ (subjective, subjective); S-DC (subjective, dashed composite); S-DR (subjective, dashed real); DC-DC (dashed composite, dashed composite); DC-S (dashed composite, subjective); DR-S (dashed real, subjective); and DR-DR (dashed real. dashed real).

Procedure. The procedures and the comparison stimuli were the same as those used in Experiment 1.

\section{Results and Discussion}

The present results were closely comparable to the results of Experiment 1. Since the means and standard deviations were also correlated here, the data were transformed by taking $\log (X+10)$. A $2 \times 7$ analysis of variance with repeated measures on both factors was then performed. The kinds of edges (bent, colinear) produced no significant main effect $(F<1)$, but there was a significant effect of figures $[F(6,90)=18.12, p<.001]$, and a significant edge $\times$ figure interaction $[F(6,90)=35.60$, $p<.001]$.

The dashed lines in Figure DR-DR, like the solid lines in Experiment 1, produced a small but significant Bourdon illusion of $1.25^{\circ}[t(15)=2.24, p<.05]$; Figure DC-DC produced an intermediate effect of $5.62^{\circ}$ $[t(15)=6.26, p<.001] ;$ and Figure $S-S$ produced a large effect of $9.69^{\circ}[t(15)=11.40, p<.001]$. The Bourdon illusion differed significantly among these figures by Newman-Keuls tests.

As in Experiment 1, real and composite induction contours produced substantial Bourdon illusions in subjective test contours in Figures S-DR and S-DCrespectively, $8.75^{\circ}$ and $12.19^{\circ}$ [both values of $t(15) \geq$ $7.52, p<.001]$. Subjective induction contours produced no significant Bourdon illusion in real or composite test contours in Figure DR-S or DC-S-respectively, $0^{\circ}$ and $0.31^{\circ}$ (both values of $t<1$ ). However, the real and composite test contours produced significant unbending in subjective induction contours in these figures $-8.44^{\circ}$ in both cases [both values of $t(15) \geq 7.73, p<.001$ ]

Subjective test contours also produced significant unbending in real and composite induction contours in Figures S-DR and S-DC- $3.44^{\circ}$ in both cases [both values of $t(15) \geq 2.91, p<.02$ ]. But the unbending in those figures was considerably less than the amount of the Bourdon illusion.

Overall, there was no significant difference between the results of Experiments 1 and 2. Pooling the results across the seven figures within these experiments, the mean Bourdon illusion was respectively $5.30^{\circ}$ and $5.40^{\circ}$, and the mean unbending effect was $4.90^{\circ}$ and $5.90^{\circ}$ [both values of $t<1$ ].

The illusion in the comparison stimuli observed in Experiment 1 also occurred here. The midpoints of the comparison lines appeared higher on the right side of the display to all 16 subjects $(Z=3.75, p<.001]$.

\section{EXPERIMENT 3}

This experiment was designed to measure the interactions between real and subjective contours produced by positive and negative luminance contrast in the Bourdon illusion. The subjective contours were produced by black and white inducing elements against a uniform gray background, and the real contours consisted of black and white lines.

\section{Method}

Subjects. Ten male and 8 female undergraduate psychology students received extra course credit for their participation in this experiment. Their ages ranged from 18 to 34 , and the mean age was 20.67. 


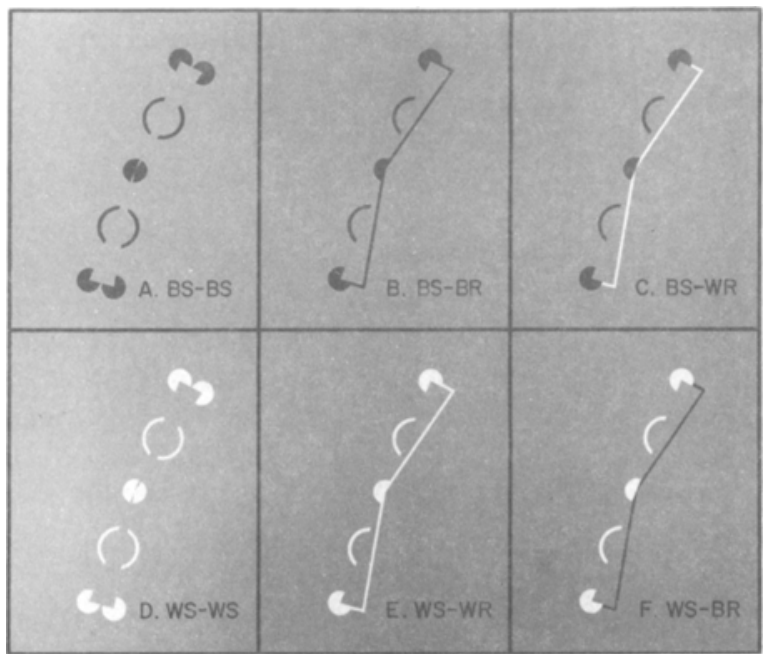

Figure 4. Illusions in Experiment 3. The first letters identify the colinear test contours and the second letters identify the bent induction contours. (A) BS-BS, black subjective, black subjective; (B) BS-BR, black subjective, black real; (C) BS-WR, black subjective, white real; (D) WS-WS, white subjective, white subjective; (E) WS-WR, white subjective, white real; and (F) WS-BR, white subjective, black real.

Stimuli. The illusions are shown in Figure 4. In Figure 4A, the test and induction contours were both subjective and were produced by black inducing elements against a gray background. In Figures $4 \mathrm{~B}$ and $4 \mathrm{C}$, the subjective test contours were produced by black inducing elements and the real induction contours were respectively black and white lines, all presented against uniform gray backgrounds. In Figures $4 \mathrm{D}, 4 \mathrm{E}$, and $4 \mathrm{~F}$, the preceding contrast relationships between illusion elements and the background were reversed.

In the present illusions, the first letters refer to the colinear test edges and the second letters refer to the bent induction edges: BS-BS (black subjective, black subjective); BS-BR (black subjective, black real); BS-WR (black subjective, white real); WS-WS (white subjective, white subjective); WS-WR (white subjective, white real); and WS-BR (white subjective, black real). Figure BS-BS was similar to Figure 1A, except the background of Figure BS-BS was gray. Figure WS-WS was also similar to Figure 1A, except the inducing elements were white against a gray background. Figures BS-BR and BS-WR were similar to Figure $1 \mathrm{C}$, in that the subjective colinear test contours were produced by black inducing elements, and the real induction contours were black lines in Figure BS-BR and white lines in Figure BS-WR.

The inducing elements and real lines in these figures were cut from matte-finish black and white paper and fixed to uniform matte gray backgrounds. The inducing elements were the same size as those in the earlier experiments, and the real lines were wider; namely, $3 \mathrm{~mm}$ in width. The reflectances of the black and white portions of the figures were $2.8 \%$ and $92.3 \%$, and the reflectance of the gray background was $34.7 \%$.

The comparison stimuli (see Figure 5) were drawn in black ink on a gray background of the same reflectance as the backgrounds of the illusions. The middle member of the comparison stimuli was a straight line, and the other members were bent $25^{\circ}$ and $50^{\circ}$ to the left and right. From left to right, the comparison lines were labeled $20 \mathrm{~L}, 10 \mathrm{~L}, 0,10 \mathrm{R}$, and $20 \mathrm{R}$.

The illusions and comparison stimuli were presented in a frontoparallel plane at a viewing distance of $2 \mathrm{~m}$. The illusions were approximately at eye level and the comparison stimuli were located immediately below. The center of the comparison display was $34 \mathrm{~cm}$ below the center of each illusion figure. The displays were lighted by overhead fluorescent lights providing a luminance of $64 \mathrm{~cd} / \mathrm{m}^{2}$ on the background of the illusions and $49 \mathrm{~cd} / \mathrm{m}^{2}$ on the comparison stimuli. The luminances of the black and white portions of the illusions were 5 and $169 \mathrm{~cd} / \mathrm{m}^{2}$, respectively. The illusions were the same size and shape as those in the earlier experiments, and the comparison stimuli were also the same size.

Procedure. The procedures were the same as in the earlier experiments except for the use of a different set of comparison stimuli. In measuring the Bourdon illusion, the experimenter asked whether the colinear test contours appeared straight or bent. If these contours appeared straight, this judgment was assigned a scale value of 0 . If the test contours appeared bent, then the subject was instructed to choose the comparison stimulus that most closely matched the appearance of the test contours. This usually resulted in a choice of Comparison 0 . The subject then indicated whether the test contours appeared bent in the direction of Comparison 10L or 10R, and then chose a scale value between 0 and $10 \mathrm{~L}$ or between 0 and $10 \mathrm{R}$ to indicate the extent of apparent bending. A larger amount of apparent bending sometimes resulted in a choice of Comparison 10R. In that case, the subject indicated whether the test contours appeared bent in the direction of Comparison 0 or 20R, and then chose a scale value between $10 R$ and 0 , or between $10 R$ and $20 R$, to indicate the extent of apparent bending. Apparent bending toward the comparison lines on the right of the display was taken as a positive Bourdon illusion.

Similar procedures were used in measuring the unbending effect. If there was no apparent displacement of the bent induction contours, then the subject would match these contours to Comparison $10 R$. If the unbending effect occurred-that is, if the bent induction contours appeared displaced toward the colinear test contours-then the subject would match these contours to a scale value of less than $10 R$. If the induction contours appeared displaced away from the test contours, then the subject would match the induction contours to a comparison greater than 10R. Apparent displacement of the bent induction contours in the direction of the colinear test contours was taken as a positive unbending effect.

\section{Results and Discussion}

The data were transformed by taking $\log (X+10)$, and a $2 \times 6$ repeated-measures analysis of variance was carried out. As in the previous experiments, the kinds of

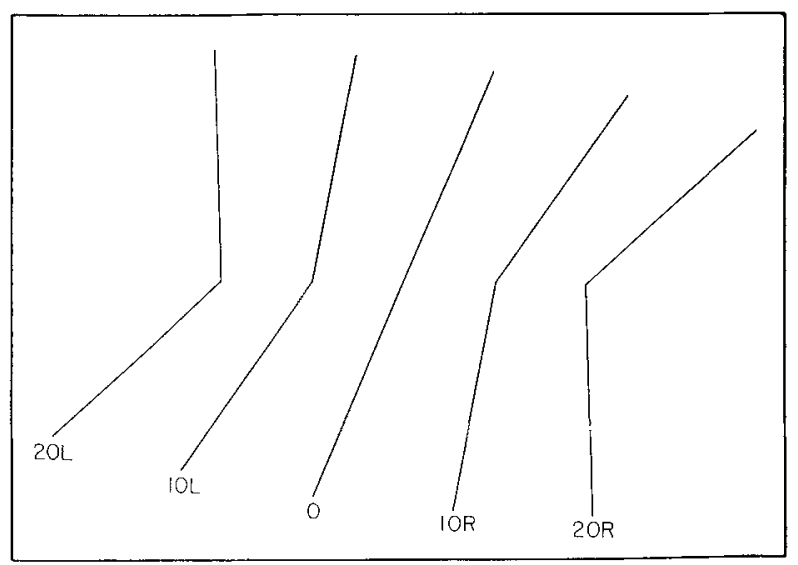

Figure 5. Comparison stimuli in Experiment 3. Comparison 0 is straight, $10 \mathrm{~L}$ and $10 \mathrm{R}$ are bent $25^{\circ}$, and $20 \mathrm{~L}$ and $20 \mathrm{R}$ are bent $50^{\circ}$. Background was gray, not white as shown here. 


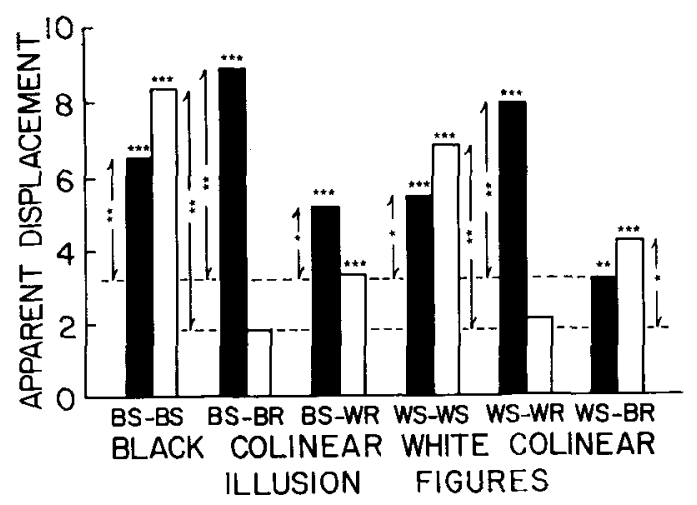

Figure 6. Results of Experiment 3. Asterisks indicate significance as in Figure 3.

edges (colinear, bent) produced no significant main effect $[F(1,17)=1.82, p<.25]$, but the effect of figures was highly significant $[F(5,85)=8.10, p<.001]$, and there was a significant edge $\times$ figure interaction $[F(5,85)$ $=9.93, p<.001]$.

Each figure produced a significant Bourdon illusion (see Figure 6). The smallest illusion was $3.18^{\circ}$ in Figure WS-BR $[t(17)=3.37, p<.01]$. In the other figures, the mean Bourdon illusion ranged from $5.15^{\circ}$ to $8.90^{\circ}$ [all values of $t(17) \geq 5.77, p<.001$ ]

The unbending effect was not significant in Figure BS-BR or WS-WR (neither value of $t>1.66$ ). But there was significant unbending ranging from $3.32^{\circ}$ to $8.32^{\circ}$ in all of the other figures [all values of $t(17) \geq$ $4.95, p<.001]$.

Selected Newman-Keuls comparisons are shown in Figure 6 . In the figures with black subjective test contours, real black induction contours produced a larger Bourdon illusion than did real white induction contours (BS-BR vs. BS-WR, $p<.01$ ). Similarly, in the figures with white subjective contours, real white induction contours produced a larger Bourdon illusion than did real black induction contours (WS-WR vs. WS-BR, $p<.01$ ). Thus, real black or white induction contours produced greater Bourdon illusions in subjective test contours created by inducing elements of the same luminance contrast as the induction contours.

The subjective colinear test contours, whether black or white, produced greater unbending in subjective induction contours than in real induction contours (NewmanKeuls, $p s<.01$ ). Thus, the interactions were asymmetrical between real and subjective contours, as in Experiments 1 and 2 . In addition, the Bourdon illusion and the unbending effect depended to some extent on the luminance contrast between the bent induction contours and the inducing elements giving rise to the colinear test contours.

The illusion described in the comparison stimuli in Experiments 1 and 2 also occurred here. For 14 of the 18 subjects, the midpoints of the bent comparison lines on the right side of the display appeared higher than on the left $(Z=2.12, p<.05)$.

\section{GENERAL DISCUSSION}

Several workers have offered cognitive explanations of subjective contours (for example, Gregory, 1972; Halpern \& Saltzman, 1983; Kanizsa, 1955, 1979; Rock \& Anson, 1979). Essentially, the cognitive view holds that subjective contours are the edges of subjective figures created by the apparent occlusion of parts of the inducing elements, as in Figure 1A. In fact, subjective figures usually do appear located slightly above the background in depth, and do appear a little brighter than the background.

Indeed, brightness contrast has been proposed as a possible explanation of subjective contours. As an empirical fact, brightness contrast does occur in connection with many subjective contours, particularly in Kanizsa figures. Black inducing elements on a white background produce a subjective figure that appears lighter than the background, and white inducing elements on a black background produce a darker subjective figure (Kanizsa, 1979). But it is not entirely clear whether the apparent lightness or darkness of the figure produces the subjective contours, or whether the subjective contours produce the apparent lightness or darkness (for example, Bradley \& Mates, 1985; Frisby \& Clatworthy, 1975; Halpern \& Saltzman, 1983; Prazdny, 1983; Ware, 1981).

Feature detectors have been invoked as possible mechanisms accounting for subjective contours, although not without criticism. In Figure 1A, the corners of the subjective triangles are determined by real luminance gradients where each apex partially occludes a black induction disk. Thus, small portions of each subjective edge are real, and these real contours should stimulate local edge detectors, such as the simple cells described by Hubel and Wiesel (1968). The real portions of a subjective edge in a Kanizsa figure are widely separated in space, but these real contours are colinear, and should excite the same complex or hypercomplex cells that are tuned for their particular orientation. However, subjective contours fail to occur in some situations in which edge detectors or other feature detectors are surely stimulated (for example, Gregory, 1972; Halpern \& Saltzman, 1983).

Whatever their origin, subjective contours have many of the characteristics of real contours. Thus, it may be that some of the processes underlying apparent displacements of real contours also apply to similar effects in subjective contours.

Using real-contour figures, Rozvany and Day (1980) found the Bourdon illusion to be greatest at $22.5^{\circ}$ from the vertical. The illusion was much reduced in vertical figures, and absent at the horizontal orientation. These workers explained this finding in terms of the oblique effect: the lower acuity for oblique orientations (Appelle, 1972). In fact, Rozvany and Day measured acuity for 
colinearity by having subjects rotate the upper half of a line so as to appear colinear with the lower half. Acuity was greatest for the horizontal and vertical orientations and lowest at $22.5^{\circ}$ from the vertical, thus paralleling the measurements of the Bourdon illusion.

Wenderoth and O'Connor (1987a, 1987b) explained the Bourdon illusion in the real edges of a solid figure as a failure to discriminate between the orientation of the judged edges of the figure, the other edges, and the average of these orientations. The confusion of these orientations resulted in the attraction or assimilation of the test contours in the direction of the induction contours. Wenderoth and O'Connor (1987b) also found the Bourdon illusion to be greatest in oblique figures and essentialiy nonexistent in horizontal and vertical figures, and they also invoked the oblique effect as a possible explanation. In outline figures, these workers observed significant repulsion effects under several conditions, which they explained in terms of neural processes involving lateral inhibition.

We now consider the apparent displacement of subjective contours. The edges of a subjective figure do not appear as strong or compelling as the edges of a real figure (Halpern, Saltzman, Harrison, \& Widaman, 1983). Furthermore, the just noticeable difference (jnd) for the perceived orientation of subjective contours is greater than the jnd for the orientation of real contours (Vogels \& Orban, 1987). Thus, the orientation of subjective contours should be less discriminable and more readily confused than the orientation of real contours, possibly accounting for the greater Bourdon illusion and unbending effect in subjective versus real contours.

When subjective contours and real lines are combined in the same illusion figures, as in Figures $1 \mathrm{C}$ and $1 \mathrm{~F}$, the orientation of the subjective contours should be less discriminable and therefore more readily confused with the orientation of the real lines. But the real lines-being stronger, and having smaller jnds for orientation-should be less subject to confusion with the weaker and more variable subjective contours. In fact, the subjective contours in these figures-whether test or induction contours-appeared strongly displaced toward the real lines, but the real lines showed little apparent displacement.

In Experiment 3, all of the test contours were subjective and were produced by black or white inducing elements on a gray background. Some of the induction contours were subjective, produced by black or white inducing elements, and some consisted of real black or white lines. The largest Bourdon illusions occurred in Figures BS-BR and WS-WR (see Figure 6), in which the subjective-contour inducing elements and the real induction contours were of the same luminance contrast.

Smaller Bourdon illusions occurred in Figures BS-WR and WS-BR, in which the subjective-contour inducing elements and the real induction contours were of opposite contrast, respectively black and white in the first figure, and white and black in the second. Thus, luminance contrast played a role in the apparent displacement of the subjective contours in Experiment 3.

Whatever mechanisms may account for subjective contours, the subjective edges of a Bourdon figure display mutual attraction or assimilation. In figures combining real and subjective contours, the real contours show little apparent displacement, whereas the subjective contours are strongly attracted by the real contours. All of these effects are consistent with the relative strength of subjective contours, and with their greater jnd for orientation, in comparison with real contours.

\section{REFERENCES}

APPELle, S. (1972). Perception of discrimination as a function of stimulus orientation: The "oblique effect"' in man and animals. Psychological Bulletin, 78, 266-278.

Bourdon, B. (1902). La perception visuelle de l'espace. Paris: Reinwald. Bradley, D. R., \& Mates, S. M. (1985). Perceptual organization and apparent brightness in subjective contour figures. Perception, 14, 645-653.

Bradley, D. R , \& Petry, H. M. (1977). Organizational determinants of subjective contour: The subjective Necker cube. American Journal of Psychology, 90, 253-262.

Coren, S., \& Girgus, J. S. (1978). Seeing is deceiving: The psychology of visual illusions. Hillsdale, NJ: Erlbaum.

FARNE, M. (1968). Alcune osservazioni con linee virtuali e margini quasi percettivi. Bolletino della Societá Italiana di Biologia Sperimentale, 44, 1613-1616.

Frisby, J. P., \& Clatworthy, J. L. (1975). Ilusory contours: Curious cases of simultaneous brightness contrast? Perception, 4, 349-357.

GIBSON, J. J., \& RADNER, M. (1937). Adaptation, after-effect, and contrast in the perception of tilted lines: I. Quantitative studies. Journal of Experimental Psychology, 20, 453-467.

Goldstein, M. B., \& Weintraub, D. L. (1972). The parallel-less Poggendorff: Virtual contours put the illusion down but not out. Perception \& Psychophysics, 11, 353-354.

Gregory, R. L. (1972). Cognitive contours. Nature, 238, 51-52.

HalPERN, D. , \& Saltzman, B. (1983). The multiple determination of illusory contours: 1. A review. Perception, 12, 281-291.

Halpern, D., Saltzman, B., Harrison, W., \& Widaman, K. (1983). The multiple determination of illusory contours: 2 . An empirical investigation. Perception, 12, 293-303.

Hubel, D. H., \& Wiesel, T. N. (1968). Receptive fields and functional architectuse of monkey striate cortex. Journal of Physiology, 195, 215-243.

JASTROW, J. (1891). A study of Zöllner's figures and other related illusions. American Joumal of Psychology, 4, 381-398.

KANIZSA, G. (1955). Margini quasi-percettivi in campi con stimolazione omogenea. Rivista di Psicologia, 49, 7-30.

Kanizsa, G. (1979). Organization in vision. New York: Praeger.

LuckIESH, M. (1965). Visual illusions. New York: Dover. (Original work published 1922)

Meyer, G. E., \& Garges, C. (1979). Subjective contours and the Poggendorff illusion. Perception \& Psychophysics, 26, 302-304.

Pastore, N. (1971). Selective history of theories of visual perception. New York: Oxford University Press.

PRAZDNY, K. (1983). Ilusory contours are not caused by simultaneous brightness contrast. Perception \& Psychophysics, 34, 403-404.

Pressey, A. W., d Den Heyer, K. (1968). Observations on Chiang's "new" theory of geometrical illusions. Perception \& Psychophysics, 4, 313-314.

Rock, I., \& ANSON, R. (1979). Illusory contours as the solution to a problem. Perception, 8, 665-681. 
Rozvany, G. I. N., \& DaY, R. H. (1980). Determinants of the Bourdon effect. Perception \& Psychophysics, 28, 39-44.

VoGels, R., ORBAN, G. A. (1987). Illusory contour orientation discrimination. Vision Research, 27, 453-467.

WALKer, J. T., \& ShaNk, M. D. (1987). The Bourdon illusion in subjective contours. Perception \& Psychophysics, 42, 15-24.

WARE, C. (1981). Subjective contours independent of subjective brightness. Perception \& Psychophysics, 29, 500-504.

WENDEROTh, P., \& O'CONNOR, T. (1987a). The effects of dispiay and observer strategy variables on Bourdon assimilation illusions. Perception, 16, 79-88.
Wenderoth, P., \& O'Connor, T. (1987b). Outline- and solid-angle orientation illusions have different determinants. Perception \& Psychophysics, 41, 45-52.

Wenderoth, P., O'Connor, T., \& Johnson, M. (1986). Expansion and contraction of outline and solid acute angles: Effects of angle magnitude, type of display, and the nature of the matching task. Perception \& Psychophysics, 39, 261-266.

(Manuscript received April 29, 1987;

revision accepted for publication December 3, 1987.) 